Article

\title{
Inhibition of Aflatoxin Production by Paraquat and External Superoxide Dismutase in Aspergillus flavus
}

\author{
Tomohiro Furukawa ${ }^{(D)}$ and Shohei Sakuda * \\ Department of Biosciences, Teikyo University, 1-1 Toyosatodai, Utsunomiya 320-8551, Japan; \\ furukawa@nasu.bio.teikyo-u.ac.jp \\ * Correspondence: sakuda@nasu.bio.teikyo-u.ac.jp; Tel.: +81-28-627-7213
}

Received: 15 January 2019; Accepted: 12 February 2019; Published: 12 February 2019

check for updates

\begin{abstract}
Aflatoxin contamination of crops is a worldwide problem, and elucidation of the regulatory mechanism of aflatoxin production, for example relative to the oxidative-antioxidative system, is needed. Studies have shown that oxidative stress induced by reactive oxygen species promotes aflatoxin production. However, superoxide has been suggested to have the opposite effect. Here, we investigated the effects of the superoxide generator, paraquat, and externally added superoxide dismutase (SOD) on aflatoxin production in Aspergillus flavus. Paraquat with an $\mathrm{IC}_{50}$ value of $54.9 \mu \mathrm{M}$ inhibited aflatoxin production without affecting fungal growth. It increased cytosolic and mitochondrial superoxide levels and downregulated the transcription of aflatoxin biosynthetic cluster genes, including aflR, a key regulatory protein. The addition of bovine $\mathrm{Cu} / \mathrm{ZnSOD}$ to the culture medium suppressed the paraquat-induced increase in superoxide levels, but it did not fully restore paraquat-inhibited aflatoxin production because bovine $\mathrm{Cu} / \mathrm{ZnSOD}$ with an $\mathrm{IC}_{50}$ value of $17.9 \mu \mathrm{g} / \mathrm{mL}$ itself inhibited aflatoxin production. Externally added bovine $\mathrm{Cu} / \mathrm{ZnSOD}$ increased the SOD activity in fungal cell extracts and upregulated the transcription of genes encoding $\mathrm{Cu} / \mathrm{ZnSOD}$ and alcohol dehydrogenase. These results suggest that intracellular accumulation of superoxide impairs aflatoxin production by downregulating afl expression, and that externally added $\mathrm{Cu} / \mathrm{ZnSOD}$ also suppresses aflatoxin production by a mechanism other than canonical superoxide elimination activity.
\end{abstract}

Keywords: aflatoxin production; Aspergillus flavus; superoxide; paraquat; superoxide dismutase

Key Contribution: The superoxide generator paraquat and externally added superoxide dismutase suppressed aflatoxin production in Aspergillus flavus.

\section{Introduction}

Aflatoxins are potent carcinogenic toxins produced mainly by Aspergillus flavus and Aspergillus parasiticus, which infect agricultural crops, including corn and peanut. Aflatoxins accumulated in crops cause mycotoxicosis in humans and domestic animals that ingest them [1,2]. Crops contaminated with aflatoxins are discarded or reduced in value, resulting in significant economic losses [3]. Many challenges are involved in the control of aflatoxin contamination; the molecular mechanism to regulate aflatoxin production level must be elucidated to optimize or develop effective preventive methods [4-6].

The enzymatic genes responsible for aflatoxin biosynthesis are located in a cluster in the genomes of A. flavus and A. parasiticus. Aflatoxins are biosynthesized from 10 acetic acid units via at least 18 reaction steps [7]. The transcription of genes encoding aflatoxin biosynthetic enzymes is positively regulated by the transcription factor AflR, whose gene is in the same cluster [8]. Environmental factors such as light and $\mathrm{pH}$, trophic factors such as carbon and nitrogen sources, and several transcription factors recognizing these cues have been found to affect aflatoxin production, but the regulatory mechanisms of these factors leading to aflatoxin production have not been clarified in detail [9-12]. 
As externally added hydrogen peroxide has been found to promote aflatoxin production in $A$. parasiticus and A. flavus, the relationship between aflatoxin production and oxidative stress caused by reactive oxygen species (ROS) has received wide attention [13-15]. ROS comprise a series of molecular species with high chemical reactivity generated from oxygen. As ROS react with macromolecules such as DNA, protein, and lipids, impairing their function, cells are equipped with antioxidant systems that protect biomolecules from ROS [16]. When the balance between antioxidant systems and ROS generation is disrupted, oxidative stress occurs. In fungal cells, superoxide, a byproduct of the mitochondrial electron transport chain, is the main source of intracellular ROS [17]. The superoxide generated is decomposed into hydrogen peroxide and oxygen by superoxide dismutase (SOD), and hydrogen peroxide is decomposed into water by antioxidant enzymes, including catalase, glutathione peroxidase, and peroxiredoxin. Free $\mathrm{Fe}^{2+}$ may react with hydrogen peroxide and produce hydroxyl radical, which is highly toxic due to its high reactivity [18].

Although excessive ROS are harmful, ROS adjusted to an appropriate level function as signaling molecules in cell proliferation and differentiation [19]. In A. parasiticus aflatoxigenic strain NRRL2999, oxygen consumption increased in the logarithmic growth phase, and the enzymatic activities of SOD and glutathione peroxidase increased synchronously with aflatoxin production [20]. However, these phenomena of oxygen consumption and antioxidant enzyme activities observed in the aflatoxigenic strain were not observed in the nontoxigenic SRRC255 strain, suggesting that elevated ROS levels due to an increase in oxygen uptake are correlated with aflatoxin production and the expression of antioxidant enzymes. Hydrogen peroxide increased aflatoxin production in A. flavus NRRL3357 in a concentration-dependent manner [14]. Antioxidants and thiol redox state modulators reduced aflatoxin production in the $A$. flavus $70 S$ (pSL82) strain [21]. These observations suggest that a decrease in the ROS level causes a decrease in aflatoxin production. On the other hand, Zaccaria et al. [22] indicated that menadione, a superoxide generator, suppressed aflatoxin production in A. flavus NRRL3357, accompanied by a decrease in SOD activity. The regulation of mycotoxin production by superoxide was also observed in Fusarium graminearum, which accumulates trichothecenes in infected grains. The superoxide generator paraquat reduced trichothecene production in several strains $[23,24]$. Furthermore, in SOD gene deletion mutants of F. graminearum, the accumulation of intracellular superoxide and reduction of trichothecene production were observed [25].

As ROS differ in terms of generation and elimination characteristics in fungal cells, as well as chemical reactivity, the effects of individual ROS on aflatoxin production must be investigated in detail to understand the regulatory mechanism of aflatoxin production by ROS. In this study, we focused on superoxide and evaluated the effects of paraquat and external SOD on aflatoxin production in $A$. flavus. We obtained paradoxical results; both paraquat and SOD suppressed aflatoxin production. In this paper, we describe the effects of superoxide generated from paraquat on mitochondrial function, reducing aflR expression, and the apparent partial internalization of external SOD into cells to suppress aflatoxin production, possibly by a function other than superoxide dismutation activity.

\section{Results}

\subsection{Effect of Paraquat on Aflatoxin Production}

When A. flavus IFM 47798 was incubated for $48 \mathrm{~h}$ at $28^{\circ} \mathrm{C}$ in potato dextrose broth (PDB) liquid medium, about 1-2 ppm aflatoxin $B_{1}$ was detected in the culture broth. The amount of aflatoxin $\mathrm{B}_{1}$ produced by the strain decreased in a concentration-dependent manner by addition of paraquat with the $\mathrm{IC}_{50}$ value of $54.9 \mu \mathrm{M}$ (Figure 1a). As the fungal mycelial dry weight was not changed significantly by $500 \mu \mathrm{M}$ paraquat, the inhibitory activity of this superoxide generator was specific to aflatoxin $B_{1}$ production. The inhibition of aflatoxin $B_{1}$ production by paraquat was thought to be due to the generation of intracellular superoxide. Therefore, we examined whether the effect of paraquat was affected by sodium ascorbate, a general antioxidant. Aflatoxin $B_{1}$ production suppressed by $100 \mu \mathrm{M}$ paraquat was significantly restored by co-addition of $>1 \mathrm{mM}$ sodium ascorbate (Figure $1 \mathrm{~b}$ ). 
Furthermore, the addition of $3 \mathrm{mM}$ sodium ascorbate without paraquat significantly promoted aflatoxin $\mathrm{B}_{1}$ production.

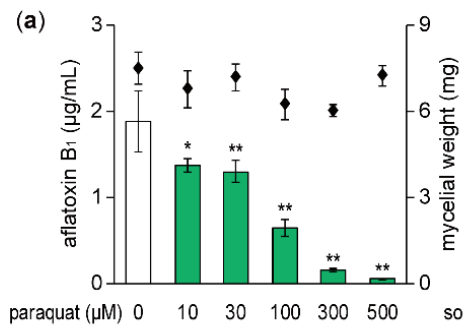

(b)

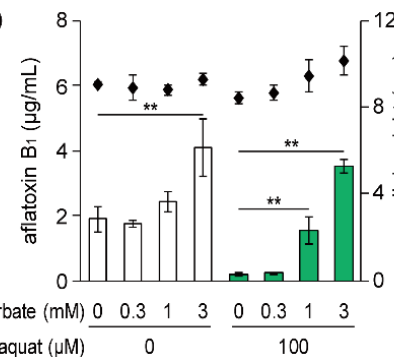

(c)

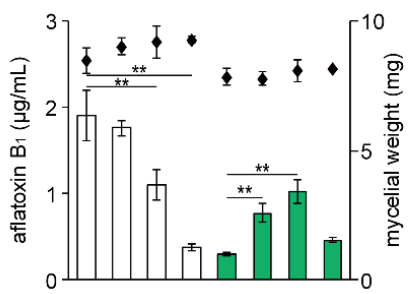

bovine Cu/ZnSOD (units) $0 \quad 30 \quad 90 \quad 300 \quad 0 \quad 30 \quad 90 \quad 300$

paraquat $(\mu \mathrm{M}) \quad 0 \quad \frac{3}{100}$

Figure 1. Effects of paraquat, sodium ascorbate, and $\mathrm{Cu} / \mathrm{Zn}$ superoxide dismutase ( $\mathrm{Cu} / \mathrm{ZnSOD})$ on aflatoxin $B_{1}$ production and fungal growth of $A$. flavus. $(\mathbf{a}-\mathbf{c})$ The amount of aflatoxin $B_{1}$ (white bars, without paraquat; green bars, with paraquat) and mycelial dry weight (squares) were analyzed. Data are presented as means and standard deviations from three biological replicates. Asterisks indicate significant differences $\left({ }^{*} P<0.05,{ }^{* *} P<0.01\right.$ vs. control group, Dunnett test).

\subsection{Effect of External SOD on Aflatoxin Production}

Next, we examined whether externally added SOD could affect the inhibition of aflatoxin production by paraquat. A. flavus was cultured with bovine $\mathrm{Cu} / \mathrm{ZnSOD}(30,90$, and 300 units $/ 2 \mathrm{~mL}$ culture) and/or paraquat, and the amount of aflatoxin $B_{1}$ produced was measured (Figure 1c). In cultures with $100 \mu \mathrm{M}$ paraquat, aflatoxin $\mathrm{B}_{1}$ production was restored to some extent by 30 and 90 units of $\mathrm{Cu} / \mathrm{ZnSOD}$ compared with no $\mathrm{Cu} / \mathrm{ZnSOD}$, but the small amount of aflatoxin production caused by paraquat was not changed by 300 units of $\mathrm{Cu} / \mathrm{ZnSOD}$. On the other hand, in cultures without paraquat, the amount of aflatoxin $\mathrm{B}_{1}$ was decreased in a concentration-dependent manner by $\mathrm{Cu} / \mathrm{ZnSOD}$ with an $\mathrm{IC}_{50}$ value of 107.3 units, corresponding to $17.9 \mu \mathrm{g}$ protein $/ \mathrm{mL}$. These results suggest that externally added $\mathrm{Cu} / \mathrm{ZnSOD}$ could decrease the amount of intracellular superoxide generated by paraquat, leading to the partial recovery of aflatoxin $\mathrm{B}_{1}$ production. However, 300 units of $\mathrm{Cu} / \mathrm{ZnSOD}$ could not suppress the effect of paraquat because its inhibitory activity on aflatoxin production was sufficiently strong to reduce the amount of aflatoxin to the level observed in the culture with $100 \mu \mathrm{M}$ paraquat alone.

\subsection{Effects of Paraquat and External SOD on mRNA Levels of Genes Responsible for Aflatoxin Biosynthesis}

A. flavus was cultured for $48 \mathrm{~h}$ with paraquat and/or $\mathrm{Cu} / \mathrm{ZnSOD}$, and mRNA levels of genes in the aflatoxin biosynthetic gene cluster were examined by real-time PCR (Figure 2). In the culture with $100 \mu \mathrm{M}$ paraquat, the mRNA levels of aflR and four genes encoding biosynthetic enzymes (AflC, AflD, AflP, and AflQ) were significantly decreased compared with the control, suggesting that the inhibition of aflatoxin $\mathrm{B}_{1}$ production by paraquat was due to suppressed transcription of the aflatoxin cluster genes. The co-addition of $\mathrm{Cu} / \mathrm{ZnSOD}$ to the culture with $100 \mu \mathrm{M}$ paraquat recovered the mRNA levels of these genes to some extent, but these levels remained lower than those in the control group. In general, addition of $\mathrm{Cu} / \mathrm{ZnSOD}$ alone did not affect the mRNA levels of these genes, with the exception of aflC. These results suggest that $\mathrm{Cu} / \mathrm{ZnSOD}$ inhibited aflatoxin $\mathrm{B}_{1}$ production without significantly affecting the transcription of most aflatoxin biosynthetic cluster genes.

\subsection{Effects of External SOD on mRNA Levels of Genes Encoding SOD and Acetyl-CoA Metabolic Enzymes}

In the genome of $A$. flavus NRRL3357, five genes were annotated as SOD genes. From the multiple alignment of amino acid sequences of the five genes (AFLA_099000, AFLA_068080, AFLA_033420, AFLA_027580, and AFLA_088150), two yeast SODs (yeast MnSOD and yeast Cu/ZnSOD [26]), and three bovine SODs (one MnSOD and two $\mathrm{Cu} / \mathrm{ZnSODs}$ ), a phylogenetic tree was created (Figure 3a). Cellular localization of the five A. flavus SODs was predicted using the TargetP 1.1 server (Figure 3a) [27]. AFLA_099000 was closest to yeast $\mathrm{Cu} / \mathrm{ZnSOD}$ and was predicted to be localized to the cytoplasm or 
nucleus. AFLA_068080 was predicted to be extracellular Cu/ZnSOD. AFLA_033420 was closest to yeast mitochondrial MnSOD and was predicted to be localized to the cytoplasm or nucleus. AFLA_027580 and AFLA_088150 were predicted to be localized to the mitochondria and annotated as FeSOD. As Fe-type SODs can utilize Fe and Mn as metal cofactors [28], which metal is utilized by these SODs is unclear. Real-time PCR analysis showed that the addition of $\mathrm{Cu} / \mathrm{ZnSOD}$ significantly increased the mRNA levels of AFLA_099000 putative Cu/ZnSOD and AFLA_068080 putative Cu/ZnSOD (Figure $3 \mathrm{~b}$ ). Conversely, the addition of 300 units $\mathrm{Cu} / \mathrm{ZnSOD}$ significantly decreased the mRNA levels of AFLA_033420 putative MnSOD and AFLA_088150 putative FeSOD. These results suggest that the external addition of $\mathrm{Cu} / \mathrm{ZnSOD}$ affected the intranuclear transcriptional regulation of the fungal intrinsic SODs.

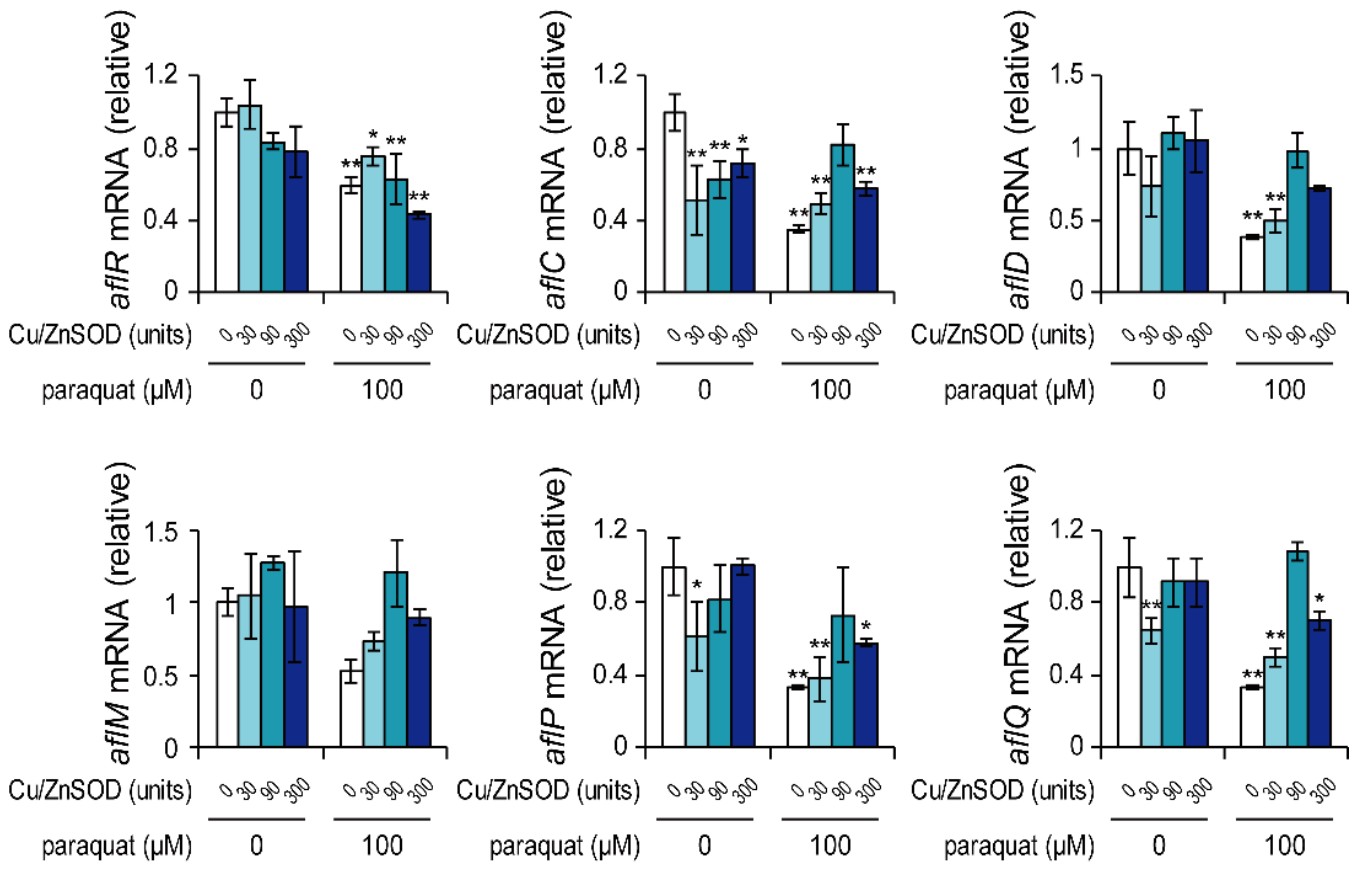

Figure 2. Effects of paraquat and $\mathrm{Cu} / \mathrm{ZnSOD}$ on the mRNA levels of aflatoxin cluster genes. Transcription of each gene was analyzed by real-time quantitative PCR. Each mRNA level was normalized to the amount of $\beta$-tubulin mRNA in each sample. Data are presented as means and standard deviations from three biological replicates. Asterisks indicate significant differences ${ }^{*} P<0.05$, ** $P<0.01$ vs. control group, Dunnett test).

In the early stage of aflatoxin biosynthesis in peroxisomes, the biosynthetic precursor acetyl-CoA could be supplied from $\beta$-oxidation in peroxisomes and mitochondria and/or acetate generated from acetaldehyde [29]. Therefore, acetaldehyde may be a key metabolite for aflatoxin production. Acetaldehyde, which is produced from pyruvate by pyruvate decarboxylase, is converted to ethanol by alcohol dehydrogenase or to acetate by aldehyde dehydrogenase. Acetate is further converted to acetyl-CoA by acetyl-CoA synthetase. Real-time PCR conducted to analyze the effect of Cu/ZnSOD on the mRNA levels of four genes encoding pyruvate decarboxylase, alcohol dehydrogenase, aldehyde dehydrogenase, and acetyl-CoA synthetase indicated that $\mathrm{Cu} / \mathrm{ZnSOD}$ significantly increased the mRNA level of AFLA_048690 putative alcohol dehydrogenase in a concentration-dependent manner (Figure 3c). This result suggests that $\mathrm{Cu} / \mathrm{ZnSOD}$ increased acetaldehyde-derived ethanol, which in turn decreased acetyl-CoA, leading to the repression of aflatoxin production. 
(a)

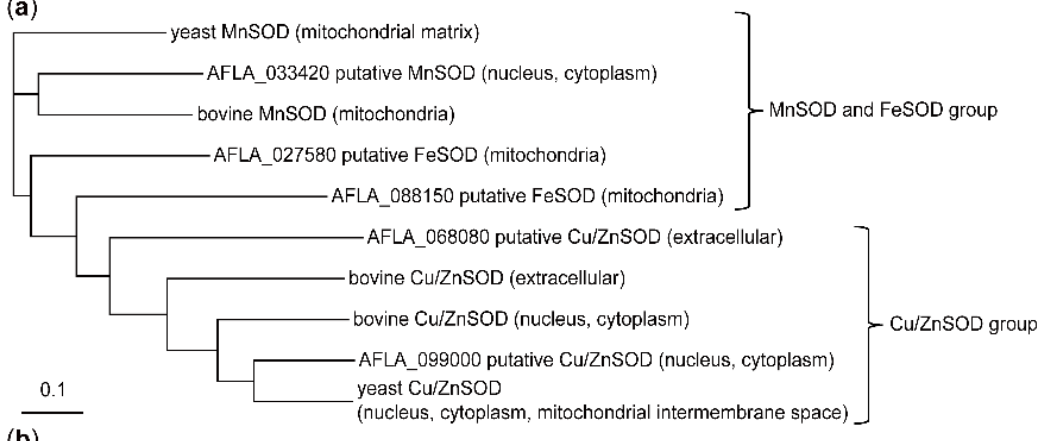

(b)

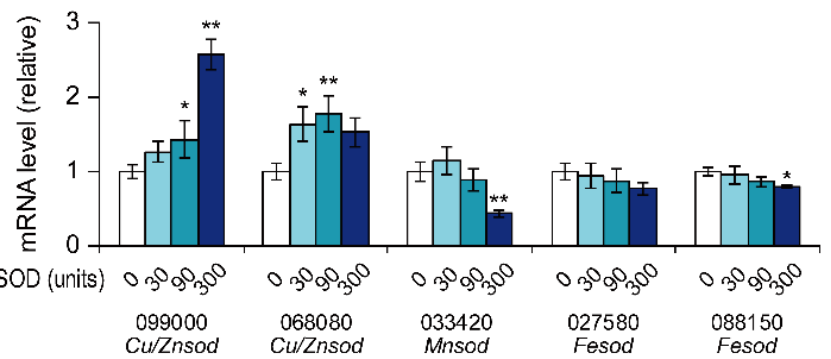

(c)

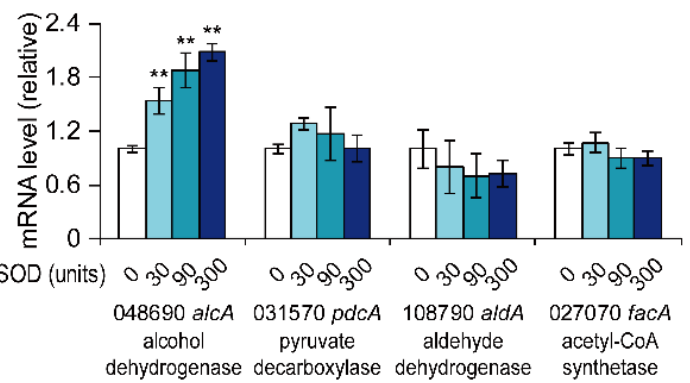

Figure 3. Phylogenetic analysis of $A$. flavus putative SOD genes and effects of $\mathrm{Cu} / \mathrm{ZnSOD}$ on the mRNA levels of these genes. (a) Amino acid sequences of five A. flavus putative SODs, two yeast SODs, and three bovine SODs were aligned using the clustal omega algorithm (provided on the website of European Bioinformatics Institute [30]). The phylogenetic tree was constructed using the neighbor-joining method. The localization of $A$. flavus SODs was predicted by the TargetP 1.1 server [27]. The localization of yeast and bovine SODs was predicted following the description on the UniProt website [31]. (b,c) Transcription of each gene was analyzed by real-time quantitative PCR. The amount of each mRNA was normalized to the amount of $\beta$-tubulin mRNA in each sample. Data are presented as means and standard deviations from three biological replicates. Asterisks indicate significant differences $\left({ }^{*} P<0.05,{ }^{* *} P<0.01\right.$ vs. control group, Dunnett test).

\subsection{SOD Activities in Fungal Cells}

To investigate whether externally added bovine $\mathrm{Cu} / \mathrm{ZnSOD}$ altered intracellular SOD activities, SOD activities in the cell extracts and culture supernatant were measured. Regardless of the presence or absence of paraquat, SOD activity was significantly greater in fungal cell extracts cultured with 300 units of $\mathrm{Cu} / \mathrm{ZnSOD}$ for $48 \mathrm{~h}$ than in cultures without $\mathrm{Cu} / \mathrm{ZnSOD}$ (Figure $4 \mathrm{a}$ ). About $0.5-1 \%$ of the SOD activity at the beginning of cultivation was detected in the fungal cell extracts; most SOD activity remained in the culture supernatant (Figure $4 \mathrm{~b}$ ), indicating that bovine $\mathrm{Cu} / \mathrm{ZnSOD}$ added to the culture remained undegraded. Next, the protein abundance of SOD was examined by western blotting of the cell extracts using an anti-human SOD1 antibody, which has cross-reactivity with bovine nucleic and cytoplasmic $15.7-\mathrm{kDa} \mathrm{Cu} / \mathrm{ZnSOD}$. Western blotting revealed bands around $17 \mathrm{kDa}$, even without the addition of bovine $\mathrm{Cu} / \mathrm{ZnSOD}$, suggesting that 16-kDa AFLA_099000 putative $\mathrm{Cu} / \mathrm{ZnSOD}$ was also detected by anti-human SOD1 antibody (Figure 4c). The density of the bands detected depended on the $\mathrm{Cu} / \mathrm{ZnSOD}$ activity depicted in Figure 4a. 
(a)

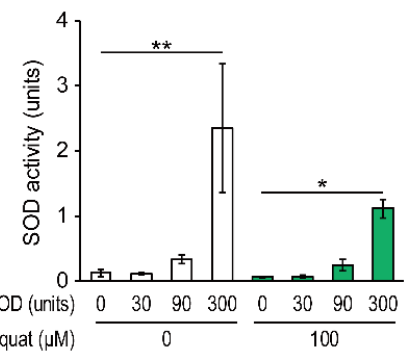

(b)

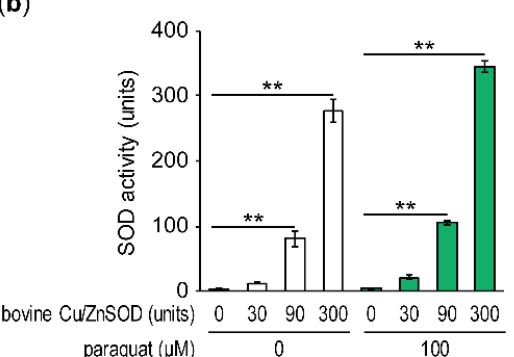

(c)

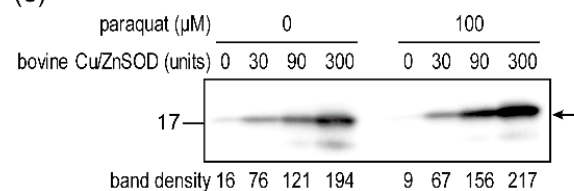

(d)

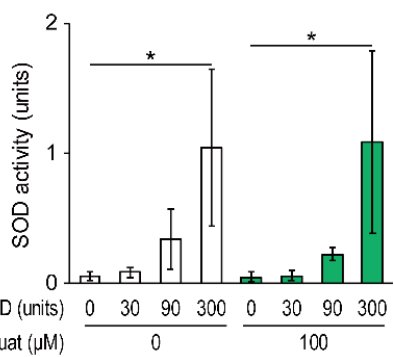

(e)

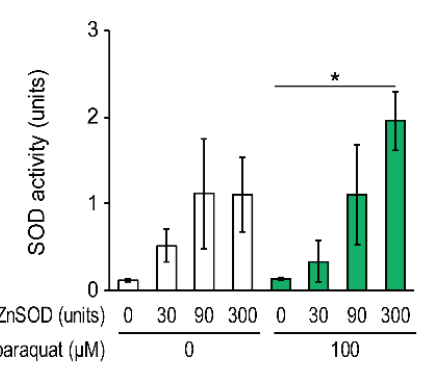

(f)

paraquat $(\mu \mathrm{M}) \quad 0 \quad 100$ bovine CuZnSOD (units) $\overline{0} 3090 \quad 300 \overline{03090300}$

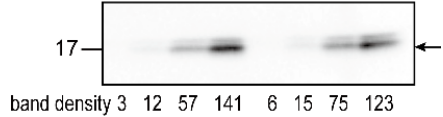

Figure 4. Determination of SOD activity and SOD protein abundance. (a-c) A. flavus was cultured for $48 \mathrm{~h}$. SOD activity of fungal cell extracts (a) and culture supernatants (b) was determined, and fungal cell extracts were subjected to western blotting using anti-human SOD1 antibody (c). The density of the bands indicated by the arrow was quantified using Image J. (d-f) After A. flavus was cultured for $24 \mathrm{~h}$, mycelia were collected, washed with distilled water, transferred to fresh medium, and incubated for another $24 \mathrm{~h}$. Then SOD activity in fungal cell extracts (d) and culture supernatant (e) was determined. Fungal cell extracts were subjected to western blotting using anti-human SOD1 antibody, and the density of the bands indicated by the arrow was quantified (f). Data are presented as means and standard deviations from three biological replicates. Asterisks indicate significant differences ( ${ }^{*}<<0.05,{ }^{* *} P<0.01$ vs. control group, Dunnett test).

To show that SOD activity was maintained in the mycelia, mycelia of $A$. flavus cultured for $24 \mathrm{~h}$ were collected, washed with water three times, and transferred to fresh medium. After cultivation in the fresh medium for another $24 \mathrm{~h}$, SOD activities in the mycelia and supernatant were measured. With and without paraquat, about 1-2 units of SOD activity were observed in each cell extract and the supernatant cultured with 300 units of $\mathrm{Cu} / \mathrm{ZnSOD}$ before washing of the mycelia (Figure 4d-f), suggesting that elevated SOD activity in fungal cells were maintained after $24 \mathrm{~h}$ cultivation.

\subsection{Effects of Paraquat and External SOD on Mitochondrial and Cytosolic Superoxide Levels}

To estimate how the intracellular superoxide level was affected by the addition of paraquat and/or $\mathrm{Cu} / \mathrm{ZnSOD}$, cellular superoxide was detected using the superoxide-specific fluorescent indicators mitoSOX and dihydroethidium (DHE), which are localized to the mitochondria and cytoplasm, respectively (Figure 5a,b and Supplementary Figure S1). In cultures treated with $100 \mu \mathrm{M}$ paraquat alone, superoxide levels in the mitochondria and cytoplasm were significantly higher than in the control after $24 \mathrm{~h}$ cultivation. These paraquat-induced high superoxide levels were suppressed by the addition of $\mathrm{Cu} / \mathrm{ZnSOD}$ in a concentration-dependent manner. In contrast, in cultures without paraquat, neither the mitochondrial nor the cytoplasmic superoxide level was changed significantly by the addition of $\mathrm{Cu} / \mathrm{ZnSOD}$ at $24 \mathrm{~h}$ cultivation. These results suggest that the external addition of $\mathrm{Cu} / \mathrm{ZnSOD}$ led to the decomposition of superoxide, the level of which had been increased by paraquat, whereas it did not affect the superoxide level during normal fungal growth. 
(a)

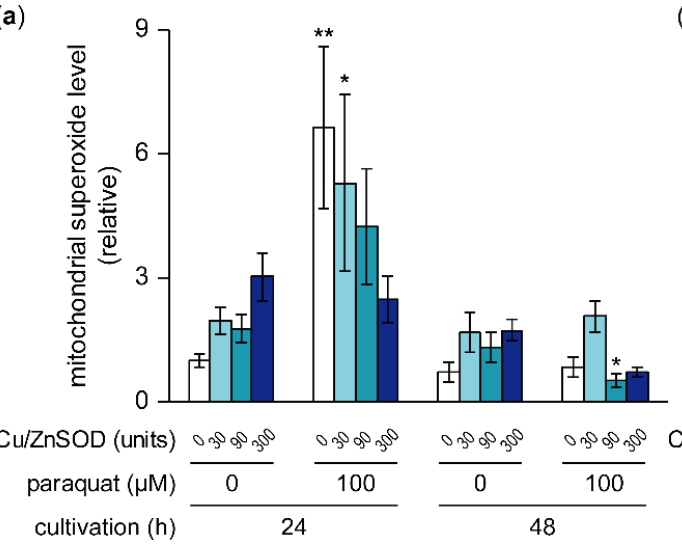

(b)

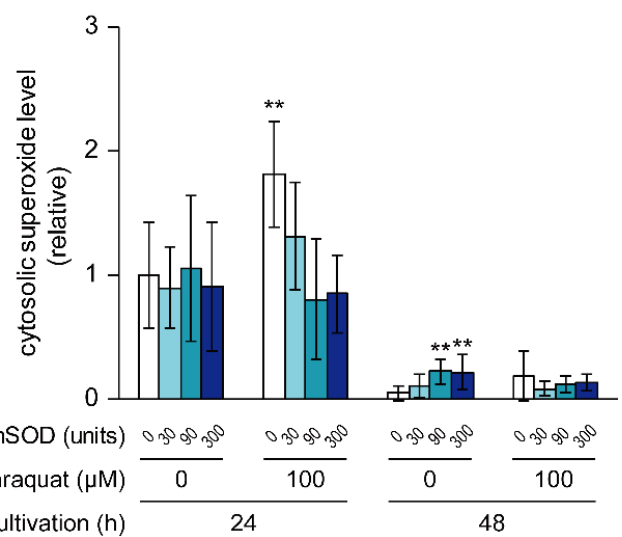

Figure 5. Effects of paraquat and $\mathrm{Cu} / \mathrm{ZnSOD}$ on mitochondrial and cytosolic superoxide levels. Time courses of mitochondrial (a) and cytosolic (b) superoxide levels in A. flavus were calculated by analyzing mitoSOX and dihydroethidium fluorescence, respectively, on microscopic images. Data are presented as means and standard deviations from eight or more microscopic images. Asterisks indicate significant differences $\left({ }^{*} P<0.05,{ }^{* *} P<0.01\right.$ vs. control group, Dunnett test).

\section{Discussion}

In some aflatoxigenic strains, aflatoxin production has been reported to be influenced by ROS; hydrogen peroxide promotes aflatoxin production, and ROS regulators such as antioxidants and intracellular ROS generator suppress it $[12-15,20,21]$. However, the manner in which individual ROS intrinsically regulate aflatoxin production needs to be clarified. In this study, we confirmed that paraquat increased superoxide levels in the mitochondria and cytoplasm, and inhibited aflatoxin $\mathrm{B}_{1}$ production by suppressing the expression of aflatoxin biosynthetic cluster genes, including aflR. In contrast to previous reports on the pSL82 strain, we found that ascorbate promoted aflatoxin $B_{1}$ production during the experiment with paraquat [21]. When bovine $\mathrm{Cu} / \mathrm{ZnSOD}$ was used for the dismutation of paraquat-induced superoxide, we observed that $\mathrm{Cu} / \mathrm{ZnSOD}$ suppressed aflatoxin $\mathrm{B}_{1}$ production in a concentration-dependent manner.

The addition of bovine $\mathrm{Cu} / \mathrm{ZnSOD}$ not only increased SOD activity in fungal cell extracts, but also increased the mRNA level of AFLA_099000 putative Cu/ZnSOD. Therefore, it was difficult to determine whether bovine $\mathrm{Cu} / \mathrm{ZnSOD}$ was internalized to increase SOD activity in the fungal cell extracts. Peñalva [32] reported that fluorescent dye FM4-64 was internalized into the cells of Aspergillus nidulans in energy-, temperature-, and F-actin-dependent manners. The fluorescence of FM4-64 was detected, in order, in cortical organelles (e.g., actin-patch), hollow structures with diameters of $0.7 \mu \mathrm{M}$ representing mature endosomes, and $2-3-\mu \mathrm{m}$-diameter vacuoles, leading the author to conclude that FM4-64 was internalized by endocytosis. Higuchi et al. [33] found that plasma membrane protein AoUapC-EGFP, the fusion protein of a putative uric acid-xanthine permease with enhanced green fluorescent protein, was internalized into the cells of Aspergillus oryzae upon the addition of ammonium. As the internalization was temperature and F-actin dependent, the authors concluded that this membrane protein was internalized by endocytosis. Based on these reports, bovine $\mathrm{Cu} / \mathrm{ZnSOD}$ could be internalized by endocytosis with other extracellular nutrients.

Increase in mitochondrial superoxide is thought to be a major cause of inhibition of aflatoxin $\mathrm{B}_{1}$ production by paraquat. Paraquat generates superoxide by oxidation of the paraquat radical, which is generated via one-electron reduction by respiratory chain or other dehydrogenases in the mitochondria [34]. Generated superoxide attacks mitochondrial (4Fe-4S) cluster enzymes, including aconitase, and releases $\mathrm{Fe}^{2+}$ from the cluster to inactivate the enzyme [35,36]. This $\mathrm{Fe}^{2+}$ release leads to the generation of hydroxyl radical, a strong oxidizing agent of macromolecules [18]. Therefore, paraquat may cause mitochondrial dysfunction. As mitochondrial respiratory inhibitors inhibit aflatoxin production [37], paraquat probably inhibits aflatoxin production through mitochondrial 
dysfunction. The relationship between mitochondrial function and the transcriptional regulation of aflatoxin biosynthetic cluster genes will be subject to further investigation.

Fluorescence observation indicated that paraquat increased mitochondrial and cytosolic superoxide, possibly through the flow of excess superoxide from the mitochondria into the cytosol through membrane channels, such as the voltage-dependent anion channel (VDAC) [17]. The addition of bovine $\mathrm{Cu} / \mathrm{ZnSOD}$ suppressed the paraquat-induced superoxide elevation in the mitochondria and cytosol, probably by increasing SOD activity.

Inhibition of aflatoxin $\mathrm{B}_{1}$ production by bovine $\mathrm{Cu} / \mathrm{ZnSOD}$ may occur due to the function of $\mathrm{Cu} / \mathrm{ZnSOD}$ as a transcription factor affecting expression of oxidative response genes. As the addition of bovine $\mathrm{Cu} / \mathrm{ZnSOD}$ without paraquat did not significantly change the mitochondrial or cytoplasmic superoxide level, the inhibition of aflatoxin production by $\mathrm{Cu} / \mathrm{ZnSOD}$ may not be correlated with SOD's canonical superoxide scavenging function. Tsang et al. [38] showed that SOD1 in human and yeast cells is phosphorylated by the Mec1/ATM kinase cascade in response to intracellular hydrogen peroxide, and that the phosphorylated SOD1 is translocated into the nucleus, where it binds to the promoters of oxidative stress-responsive genes and promotes their transcription. Yeast por- 1 encodes VDAC1, and growth of its disruptant is restricted under non-fermentable carbon source. Magrì et al. [39] found that overexpression of human SOD1 restored the growth of the disruptant in the presence of glycerol as a single carbon source. They concluded that human SOD1 entered the nucleus and increased transcription of the por-2 gene, which encodes the mitochondrial outer membrane $\beta$-barrel VDAC2, resulting in the partial recovery of mitochondrial outer membrane function. If bovine $\mathrm{Cu} / \mathrm{ZnSOD}$ is internalized, it may be transferred to the nucleus, where it would control the transcription of oxidative stress-responsive genes, including AFLA_099000 encoding cytosolic $\mathrm{Cu} / \mathrm{ZnSOD}$. If bovine $\mathrm{Cu} / \mathrm{ZnSOD}$ is not internalized, the way in which it increases the mRNA levels of AFLA_099000 in a dose-dependent manner is not clear, but the SOD increase caused by bovine $\mathrm{Cu} / \mathrm{ZnSOD}$ might affect the transcription of some genes.

The addition of bovine $\mathrm{Cu} / \mathrm{ZnSOD}$ significantly increased transcription of the alcohol dehydrogenase gene. This increased alcohol dehydrogenase activity might promote the conversion of acetaldehyde to ethanol, resulting in decreased acetyl-CoA and aflatoxin $\mathrm{B}_{1}$ production. Work investigating whether bovine $\mathrm{Cu} / \mathrm{ZnSOD}$ enters the nucleus and binds to the promoter regions of some $A$. flavus genes is now in progress.

\section{Conclusions}

This study clarified that paraquat induces intracellular accumulation of superoxide, affects aflR expression, and reduces aflatoxin production. Externally added bovine $\mathrm{Cu} / \mathrm{ZnSOD}$ suppressed the paraquat-induced increase in superoxide levels and partially restored aflatoxin production. However, bovine $\mathrm{Cu} / \mathrm{ZnSOD}$ itself can inhibit aflatoxin production by a mechanism other than its superoxide elimination activity.

\section{Materials and Methods}

\subsection{Chemicals}

Aflatoxin $\mathrm{B}_{1}$ standard, paraquat, sodium ascorbate, and lyophilized powder of $\mathrm{Cu} / \mathrm{ZnSOD}$ from bovine erythrocytes were purchased from Sigma-Aldrich (\#S7571; St Louis, MO, USA). MitoSOX and DHE were purchased from Thermo Fisher Scientific (Waltham, MA, USA). Paraquat and sodium ascorbate were dissolved in water to be $100 \mathrm{mM}$ and $3 \mathrm{M}$, respectively. Bovine $\mathrm{Cu} / \mathrm{ZnSOD}$ was dissolved in phosphate buffered saline (pH7.4) to be $10 \mathrm{U} / \mu \mathrm{L}$. According to Sigma-Aldrich, one unit will inhibit reduction of cytochrome $\mathrm{c}$ by $50 \%$ in a coupled system with xanthine oxidase at $\mathrm{pH} 7.8$ at $25^{\circ} \mathrm{C}$ in a $3.0 \mathrm{~mL}$ reaction volume. Enzyme concentration is about $3000 \mathrm{units} / \mathrm{mg}$ protein. 


\subsection{Strain and Culture Conditions}

Aspergillus flavus IFM 47798 strain (obtained from Agricultural research service, USDA, USA), which mainly produces aflatoxin $B_{1}$, was used throughout this study. A glycerol solution suspending spores collected from a week-old culture plate was used as an inoculum. The spore suspension was inoculated into PDB (BD, Sparks, MD, USA) liquid medium in a 12-well microplate ( $2 \mathrm{~mL} /$ well) at $10^{5}$ spores/well, and the microplate was placed at $28^{\circ} \mathrm{C}$ in the dark for $48 \mathrm{~h}$. When adding paraquat or sodium ascorbate, $2 \mu \mathrm{L}$ of diluted solution was added in $2 \mathrm{~mL}$ culture. When adding bovine $\mathrm{Cu} / \mathrm{ZnSOD}, 30 \mu \mathrm{L}$ of diluted solution was added. When replacing the culture medium at $24 \mathrm{~h}$ of cultivation, the culture broth of each well was centrifuged to obtain mycelia. After mycelia were washed three times with distilled water, mycelia were transferred into 12-well microplate in which each well was filled with $2 \mathrm{~mL}$ of fresh PDB liquid medium. Then the plate was placed at $28^{\circ} \mathrm{C}$ for another $24 \mathrm{~h}$.

\subsection{Analysis of Aflatoxin $B_{1}$ Production and Mycelial Weight}

After incubation, the culture broth of each well was centrifuged to obtain culture supernatant and mycelia. The $500 \mu \mathrm{L}$ of supernatant was extracted with $500 \mu \mathrm{L}$ of chloroform and the chloroform solution was evaporated in the air. The remaining residue was dissolved in $100 \mu \mathrm{L}$ of $90 \%$ aqueous acetonitrile and subjected to reverse-phase HPLC analysis according to the method previously reported [37]. The mycelia were washed with distilled water and lyophilized. The dried mycelia were weighed.

\subsection{Determination of SOD Activity}

Lyophilized mycelia were ground under liquid nitrogen with mortar and pestle and homogenate was suspended in $200 \mu \mathrm{L}$ of assay buffer (150 mM sucrose, $20 \mathrm{mM}$ Tris- $\mathrm{HCl}$ (pH 8.0), $1 \mathrm{mM}$ EDTA, $0.1 \%$ nonidet P-40). The suspension was centrifuged and supernatant was diluted to $1 / 25$ in PBS and its SOD activity was determined using SOD assay kit-WST (Dojindo, Kumamoto, Japan) according to the manufacturer's instructions. For the culture supernatants, SOD activity was similarly determined using $20 \mu \mathrm{L}$ of culture supernatants.

\subsection{Western Blotting}

Ten microliters of supernatants of mycelial homogenate suspension described above was subjected to SDS-PAGE and the separated proteins on the gel were transferred to polyvinylidene difluoride (PVDF) membrane. The membrane was immuno-blotted using anti-SOD1 antibody (SPC-115C; StressMarq Biosciences, British Columbia, Canada) followed by goat anti-rabbit IgG $(\mathrm{H}+\mathrm{L})$ poly-horseradish peroxidase antibody (32260; Thermo Fisher Scientific). The membrane was developed by ECL prime western blotting detection reagent (GE healthcare, Buckinghamshire, UK) and detected with ChemiDoc XRS+ system (Bio-Rad, Hercules, CA, USA). The density of the bands was relatively quantified using Image J software (US National Institutes of Health, Bethesda, MD, USA).

\subsection{RT-qPCR Analysis}

Lyophilized mycelia were ground as described above. Total RNA was extracted by TRIzol reagent (Thermo Fisher Scientific) and purified using PureLink RNA Mini Kit (Thermo Fisher Scientific). Complementary DNA was synthesized with ReverTra Ace qPCR Master Mix (Toyobo, Osaka, Japan). RT-qPCR was carried out using FastStart Universal SYBR Green Master (Rox) (Roche, Basel, Switzerland) in a final volume of $25 \mu \mathrm{L}$ for each reaction and ABI PRISM 7300 thermal cycler (Thermo Fisher Scientific). The amount of each mRNA was normalized to the amount of $\beta$-tubulin (NCBI gene symbol: AFLA_068620) mRNA in each sample. PCR primers used were listed in Supplementary Table S1. 


\subsection{Determination of Superoxide Level}

Mitochondrial and cytosolic superoxide levels were quantified in the same manner as previously reported method [25] with some modifications. A. flavus was cultured for 24 or 48 hand mycelia were harvested by filtration, washed with distilled water, and incubated with $5 \mu \mathrm{M}$ mitoSOX or $30 \mu \mathrm{M}$ DHE for the detection of superoxide in mitochondria and cytosol, respectively. Then the mycelia were incubated with $3 \mu \mathrm{M}$ Calcofluor White M2R (Sigma-Aldrich) and applied to microscopic slides. A BX53 fluorescence microscope equipped with a DP70 camera (Olympus, Tokyo, Japan) was used to capture fluorescent images. Superoxide level in a region of interest was estimated as follows: Using Image J software, the blue component of each fluorescent image of Calcofluor White M2R was binarized and the dimensions of the binarized area were regarded as mycelial mass in the image. Similarly, the red component of each fluorescent image of mitoSOX and DHE was first subjected to background subtraction and then binarized at the threshold set at " 20 ". The dimensions of the binarized area were regarded as superoxide amount in the image. The relative superoxide level was calculated with the equation: superoxide level in the image $=$ superoxide amount $/$ mycelial mass $\times 100$. Supplementary Figure S2 shows schematic representation of quantification of superoxide in a region of interest.

\subsection{Statistical Analysis}

Data are presented with the mean \pm standard deviation (SD). Differences between groups were analyzed by one-way ANOVA followed by the Dunnett test. Values of $P<0.05$ were considered to be significant.

Supplementary Materials: The following are available online at http:/ / www.mdpi.com/2072-6651/11/2/107/s1, Figure S1: Representative fluorescence microscopic images of fungi double-stained by Calcofluor White M2R and superoxide indicator. Figure S2: Schematic representation of quantification of superoxide in a region of interest. Table S1: Primers used in the real-time PCR analysis.

Author Contributions: Conceptualization, T.F. and S.S.; methodology, T.F.; software, T.F.; validation, T.F. and S.S.; formal analysis, T.F.; investigation, T.F.; resources, T.F.; data curation, T.F.; writing —original draft preparation, T.F.; writing—review and editing, T.F. and S.S.; visualization, T.F.; supervision, S.S.; project administration, S.S.; funding acquisition, S.S.

Funding: This research received no external funding.

Conflicts of Interest: The authors declare no conflicts of interest.

\section{References}

1. Bennett, J.W.; Klich, M. Mycotoxins. Clin. Microbiol. Rev. 2003, 16, 497-516. [CrossRef] [PubMed]

2. Liu, Y.; Wu, F. Global burden of Aflatoxin-induced hepatocellular carcinoma: A risk assessment. Environ. Health Perspect. 2010, 118, 818-824. [CrossRef] [PubMed]

3. Mitchell, N.J.; Bowers, E.; Hurburgh, C.; Wu, F. Potential economic losses to the US corn industry from aflatoxin contamination. Food Addit. Contam. Part A 2016, 33, 540-550. [CrossRef] [PubMed]

4. Ehrlich, K.C. Non-aflatoxigenic Aspergillus flavus to prevent aflatoxin contamination in crops: Advantages and limitations. Front. Microbiol. 2014, 5, 1-9. [CrossRef] [PubMed]

5. Villers, P. Aflatoxins and safe storage. Front. Microbiol. 2014, 5, 1-6. [CrossRef] [PubMed]

6. Cary, J.W.; Rajasekaran, K.; Brown, R.L.; Luo, M.; Chen, Z.-Y.; Bhatnagar, D. Developing resistance to aflatoxin in maize and cottonseed. Toxins (Basel) 2011, 3, 678-696. [CrossRef] [PubMed]

7. Yabe, K.; Nakajima, H. Enzyme reactions and genes in aflatoxin biosynthesis. Appl. Microbiol. Biotechnol. 2004, 64, 745-755. [CrossRef] [PubMed]

8. Ehrlich, K.C.; Montalbano, B.G.; Cary, J.W. Binding of the C6-zinc cluster protein, AFLR, to the promoters of aflatoxin pathway biosynthesis genes in Aspergillus parasiticus. Gene 1999, 230, 249-257. [CrossRef]

9. Bayram, O.; Krappmann, S.; Ni, M.; Bok, J.W.; Helmstaedt, K.; Valerius, O.; Braus-Stromeyer, S.; Kwon, N.-J.; Keller, N.P.; Yu, J.-H.; et al. VelB/VeA/LaeA complex coordinates light signal with fungal development and secondary metabolism. Science 2008, 320, 1504-1506. [CrossRef] 
10. Tilburn, J.; Sarkar, S.; Widdick, D.A.; Espeso, E.A.; Orejas, M.; Mungroo, J.; Peñalva, M.; Arst, H.N., Jr. The Aspergillus PacC zinc finger transcription factor mediates regulation of both acid- and alkaline-expressed genes by ambient pH. EMBO J. 1995, 14, 779-790. [CrossRef]

11. Ehrlich, K.C.; Montalbano, B.G.; Cary, J.W.; Cotty, P.J. Promoter elements in the aflatoxin pathway polyketide synthase gene. Biochim. Biophys. Acta 2002, 1576, 171-175. [CrossRef]

12. Reverberi, M.; Zjalic, S.; Ricelli, A.; Punelli, F.; Camera, E.; Fabbri, C.; Picardo, M.; Fanelli, C.; Fabbri, A.A. Modulation of antioxidant defense in Aspergillus parasiticus is involved in aflatoxin biosynthesis: A role for the ApyapA gene. Eukaryot. Cell 2008, 7, 988-1000. [CrossRef]

13. Narasaiah, K.V.; Sashidhar, R.B.; Subramanyam, C. Biochemical analysis of oxidative stress in the production of aflatoxin and its precursor intermediates. Mycopathologia 2006, 162, 179-189. [CrossRef]

14. Fountain, J.C.; Scully, B.T.; Chen, Z.-Y.; Gold, S.E.; Glenn, A.E.; Abbas, H.K.; Lee, R.D.; Kemerait, R.C.; Guo, B. Effects of hydrogen peroxide on different toxigenic and atoxigenic isolates of Aspergillus flavus. Toxins (Basel) 2015, 7, 2985-2999. [CrossRef] [PubMed]

15. Fountain, J.C.; Koh, J.; Yang, L.; Pandey, M.K.; Nayak, S.N.; Bajaj, P.; Zhuang, W.-J.; Chen, Z.-Y.; Kemerait, R.C.; Lee, R.D.; et al. Proteome analysis of Aspergillus flavus isolate-specific responses to oxidative stress in relationship to aflatoxin production capability. Sci. Rep. 2018, 8, 1-14. [CrossRef] [PubMed]

16. Apel, K.; Hirt, H. Reactive oxygen species: Metabolism, oxidative stress, and signal transduction. Annu. Rev. Plant Biol. 2004, 55, 373-399. [CrossRef] [PubMed]

17. Lustgarten, M.S.; Bhattacharya, A.; Muller, F.L.; Jang, Y.C.; Shimizu, T.; Shirasawa, T.; Richardson, A.; Van Remmen, H. Complex I generated, mitochondrial matrix-directed superoxide is released from the mitochondria through voltage dependent anion channels. Biochem. Biophys. Res. Commun. 2012, 422, 515-521. [CrossRef]

18. Liochev, S.I.; Fridovich, I. Superoxide and iron: Partners in crime. IUBMB Life 1999, 48, 157-161. [CrossRef]

19. D'Autréaux, B.; Toledano, M.B. ROS as signalling molecules: Mechanisms that generate specificity in ROS homeostasis. Nat. Rev. Mol. Cell Biol. 2007, 8, 813-824. [CrossRef]

20. Jayashree, T.; Subramanyam, C. Oxidative stress as a prerequisite for aflatoxin production by Aspergillus parasiticus. Free Radic. Biol. Med. 2000, 29, 981-985. [CrossRef]

21. Grintzalis, K.; Vernardis, S.I.; Klapa, M.I.; Georgiou, C.D. Role of oxidative stress in sclerotial differentiation and aflatoxin B1 biosynthesis in Aspergillus flavus. Appl. Environ. Microbiol. 2014, 80, 5561-5571. [CrossRef] [PubMed]

22. Zaccaria, M.; Ludovici, M.; Sanzani, S.M.; Ippolito, A.; Cigliano, R.A.; Sanseverino, W.; Scarpari, M.; Scala, V.; Fanelli, C.; Reverberi, M. Menadione-induced oxidative stress re-shapes the oxylipin profile of Aspergillus flavus and its lifestyle. Toxins (Basel) 2015, 7, 4315-4329. [CrossRef] [PubMed]

23. Ponts, N.; Pinson-Gadais, L.; Verdal-Bonnin, M.-N.; Barreau, C.; Richard-Forget, F. Accumulation of deoxynivalenol and its 15 -acetylated form is significantly modulated by oxidative stress in liquid cultures of Fusarium graminearum. FEMS Microbiol. Lett. 2006, 258, 102-107. [CrossRef] [PubMed]

24. Furukawa, T.; Sakamoto, N.; Suzuki, M.; Kimura, M.; Nagasawa, H.; Sakuda, S. Precocene II, a trichothecene production inhibitor, binds to voltage-dependent anion channel and increases the superoxide level in mitochondria of Fusarium graminearum. PLoS ONE 2015, 10, e0135031. [CrossRef] [PubMed]

25. Furukawa, T.; Yoshinari, T.; Sakuda, S. Intracellular superoxide level controlled by manganese superoxide dismutases affects trichothecene production in Fusarium graminearum. FEMS Microbiol. Lett. 2017, 364, 1-8. [CrossRef] [PubMed]

26. Chung, W.H. Unraveling new functions of superoxide dismutase using yeast model system: Beyond its conventional role in superoxide radical scavenging. J. Microbiol. 2017, 55, 409-416. [CrossRef] [PubMed]

27. Emanuelsson, O.; Nielsen, H.; Brunak, S.; von Heijne, G. Predicting subcellular localization of proteins based on their N-terminal amino acid sequence. J. Mol. Biol. 2000, 300, 1005-1016. [CrossRef] [PubMed]

28. Miller, A.F. Superoxide dismutases: Ancient enzymes and new insights. FEBS Lett. 2012, 586, 585-595. [CrossRef]

29. Chanda, A.; Roze, L.V.; Kang, S.; Artymovich, K.A.; Hicks, G.R.; Raikhel, N.V.; Calvo, A.M.; Linz, J.E. A key role for vesicles in fungal secondary metabolism. Proc. Natl. Acad. Sci. USA 2009, 106, 19533-19538. [CrossRef] [PubMed]

30. European Bioinformatics Institute. Available online: https://www.ebi.ac.uk/Tools/msa/clustalo/ (accessed on 15 January 2019). 
31. UniProtKB. Available online: https:/ / www.uniprot.org/ (accessed on 15 January 2019).

32. Peñalva, M.A. Tracing the endocytic pathway of Aspergillus nidulans with FM4-64. Fungal Genet. Biol. 2005, 42, 963-975. [CrossRef]

33. Higuchi, Y.; Nakahama, T.; Shoji, J.; Arioka, M.; Kitamoto, K. Visualization of the endocytic pathway in the filamentous fungus Aspergillus oryzae using an EGFP-fused plasma membrane protein. Biochem. Biophys. Res. Commun. 2006, 340, 784-791. [CrossRef] [PubMed]

34. Nikiforova, A.B.; Saris, N.-E.L.; Kruglov, A.G. External mitochondrial NADH-dependent reductase of redox cyclers: VDAC1 or Cyb5R3? Free Radic. Biol. Med. 2014, 74, 74-84. [CrossRef] [PubMed]

35. Flint, D.H.; Tuminello, J.F.; Emptage, M.H. The inactivation of Fe-S cluster containing hydro-lyases by superoxide. J. Biol. Chem. 1993, 268, 22369-22376. [PubMed]

36. Breitenbach, M.; Rinnerthaler, M.; Hartl, J.; Stincone, A.; Vowinckel, J.; Breitenbach-Koller, H.; Ralser, M. Mitochondria in ageing: There is metabolism beyond the ROS. FEMS Yeast Res. 2014, 14, 198-212. [CrossRef] [PubMed]

37. Sakuda, S.; Prabowo, D.F.; Takagi, K.; Shiomi, K.; Mori, M.; Omura, S.; Nagasawa, H. Inhibitory effects of respiration inhibitors on aflatoxin production. Toxins (Basel) 2014, 6, 1193-1200. [CrossRef] [PubMed]

38. Tsang, C.K.; Liu, Y.; Thomas, J.; Zhang, Y.; Zheng, X.F.S. Superoxide dismutase 1 acts as a nuclear transcription factor to regulate oxidative stress resistance. Nat. Commun. 2014, 5, 1-11. [CrossRef] [PubMed]

39. Magrì, A.; Rosa, M.C.D.; Tomasello, M.F.; Guarino, F.; Reina, S.; Messina, A.; Pinto, V.D. Overexpression of human SOD1 in VDAC1-less yeast restores mitochondrial functionality modulating beta-barrel outer membrane protein genes. Biochim. Biophys. Acta 2016, 1857, 789-798. [CrossRef]

(C) 2019 by the authors. Licensee MDPI, Basel, Switzerland. This article is an open access article distributed under the terms and conditions of the Creative Commons Attribution (CC BY) license (http:// creativecommons.org/licenses/by/4.0/). 